\title{
Low-Cycle Fatigue Behaviour of a Ni-Based Single-Crystal Superalloy
}

\author{
Mikael Segersäll, Johan Moverare, Daniel Leidermark and Kjell Simonsson
}

\section{Linköping University Post Print}

\section{Tweet}

N.B.: When citing this work, cite the original article.

Original Publication:

Mikael Segersäll, Johan Moverare, Daniel Leidermark and Kjell Simonsson, Low-Cycle Fatigue Behaviour of a Ni-Based Single-Crystal Superalloy, 2014, Advanced Materials Research, (891-892), 416-421.

http://dx.doi.org/10.4028/www.scientific.net/AMR.891-892.416

Copyright: Trans Tech Publications http://www.ttp.net/

Postprint available at: Linköping University Electronic Press http://urn.kb.se/resolve?urn=urn:nbn:se:liu:diva-104750 


\title{
Low-cycle fatigue behaviour of a Ni-based single-crystal superalloy
}

\author{
Mikael Segersäll ${ }^{1, \mathrm{a}}$, Johan J. Moverare ${ }^{1,2, \mathrm{~b}}$, Daniel Leidermark ${ }^{1, \mathrm{c}}$, \\ and Kjell Simonsson ${ }^{1, d}$ \\ ${ }^{1}$ Linköping University, Dept. Management and Engineering, SE-58183 Linköping, Sweden \\ ${ }^{2}$ Siemens Industrial Turbomachinery, Materials Technology, SE-61283 Finspång, Sweden \\ amikael.segersall@liu.se, bjohan.moverare@liu.se, cdaniel.leidermark@liu.se, \\ ${ }^{\mathrm{d}}$ kjell.simonsson@liu.se
}

Keywords: Ni-based single-crystal superalloy, LCF, tension/compression asymmetry, serrated yielding.

\begin{abstract}
In this study, low-cycle fatigue (LCF) tests at $500{ }^{\circ} \mathrm{C}$ in the $\langle 001\rangle,\langle 011\rangle$ and $\langle 111\rangle$ directions have been performed for the Ni-based single-crystal superalloy MD2. All tests were carried out in strain control with $R_{\epsilon}=-1$. The $\langle 001\rangle$ direction has the lowest stiffness of the three directions and also shows the best fatigue properties in this study followed by the $\langle 011\rangle$ and $\langle 111\rangle$ directions, respectively. It is well recognised that Ni-based single-crystal superalloys show a tension/compression asymmetry in yield strength and this study shows that a tension/compression asymmetry also is prevalent during LCF conditions. At mid-life, the $\langle 001\rangle$ direction generally has a higher stress in tension than in compression, while the opposite is true for the $\langle 011\rangle$ direction. For the $\langle 111\rangle$ direction the asymmetry is found to be strain range dependent. The $\langle 011\rangle$ and $\langle 111\rangle$ directions show a cyclic hardening behaviour when comparing cyclic stress-strain curves with monotonic stress-strain curves. In addition, the $\langle 011\rangle$ and $\langle 111\rangle$ directions show a serrated yielding behaviour for a number of cycles while the yielding of the $\langle 001\rangle$ direction is more stable.
\end{abstract}

\section{Introduction}

Ni-based single-crystal superalloys are used as blade material in gas turbines and aero engines thanks to their excellent mechanical and chemical properties at elevated temperatures [1]. Excellent fatigue and creep properties are important since the blades are subjected to extreme mechanical loads and high temperatures over long times and this makes Ni-based superalloys the only considerable option in these applications. Ni-based superalloys consist of the typical $\gamma / \gamma^{\prime}$-microstructure where precipitates of $\gamma^{\prime}$ are surrounded by a matrix of $\gamma$. Single-crystal turbine blades are always casted with their $\langle 001\rangle$ direction upwards since this is the preferred growth direction but also due to the low stiffness shown by this direction. During strain-controlled fatigue conditions, a material with a low stiffness is favoured and research shows that the LCF lives decreases in the order $\langle 001\rangle,\langle 011\rangle$ and $\langle 111\rangle$ [2]. However, cracks can sometimes be visible on the blade platform and the propagation of these cracks is dependent on properties in other directions, for example the $\langle 011\rangle$ direction. At the upper part of the gas turbine blade, the temperatures can sometimes reach $1000{ }^{\circ} \mathrm{C}$, where the highest temperature is recorded on the blade tip. At these parts of the blade, the high temperature makes the microstructure unstable meaning that the temperature variations will have an influence on the fatigue life. This means that thermomechanical fatigue (TMF) testing, where both temperature and load are cycled at the same time, must be considered to fully understand the fatigue properties [3, 4]. However, further down on the blade, e. g. at the blade foot, the temperature is lower, approximately $500{ }^{\circ} \mathrm{C}$, meaning that the microstructure will remain rather stable during the temperature variations. Therefore, LCF testing is enough when trying to understand the fatigue properties at these parts of the turbine blade.

Previous research by Gabb et al. [5] shows that single-crystal superalloys exhibit cyclic hardening due to dislocation interactions in the $\gamma$-matrix during LCF at $650{ }^{\circ} \mathrm{C}$. The same author also performed LCF tests at $1050{ }^{\circ} \mathrm{C}$ instead showing a cyclic softening [6]. This softening was explained by the creation of dislocation networks at the $\gamma / \gamma^{\prime}$-interface and a slower time-dependent coarsening 
of the $\gamma^{\prime}$-precipitates. It is a well known fact that Ni-based single-crystal superalloys show a tension/compression asymmetry in yield strength [7,8]. During LCF testing with $R_{\epsilon}=-1$ this asymmetry will have an influence since the stress levels will be different in tension compared to compression.

The aim of this study is to investigate the differences in fatigue behaviour between different crystal orientations of a Ni-based single-crystal superalloy when it is subjected to LCF conditions at $500{ }^{\circ} \mathrm{C}$. Both the mechanical response and microstructural features are considered.

\section{Experimental}

In this study the Ni-based single-crystal superalloy MD2 with chemical composition Ni, 5.1 Co, 6.0 Ta, 8.0 Cr, 8.1 W, 5.0 Al, 1.3 Ti, 2.1 Mo, 0.1 Hf and 0.1 Si (in wt. \%) was considered. Prior testing, the material was solution heat treated at $1290{ }^{\circ} \mathrm{C}$ for $8 \mathrm{~h}$, followed by a two-stage ageing process with $3 \mathrm{~h}$ at $1100{ }^{\circ} \mathrm{C}$ and $24 \mathrm{~h}$ at $850{ }^{\circ} \mathrm{C}$ in order to obtain the desirable microstructure with $\gamma^{\prime}$-cuboids in a matrix of $\gamma$. Test specimens were machined from cast bars in three different crystal orientations: the $\langle 001\rangle,\langle 011\rangle$ and $\langle 111\rangle$ directions, respectively. For each direction, four specimens were tested at different mechanical strain ranges, $\Delta \epsilon_{\text {mech }}$, which were chosen in order to obtain similar fatigue lives for all directions. The strain-controlled LCF tests with an $R_{\epsilon}=-1$ at $500{ }^{\circ} \mathrm{C}$ were performed in an Instron servo-hydraulic machine with a strain rate of $6 \%$ per min where the machine was carefully aligned to prevent specimen buckling during the tests. After the tests, each specimen was investigated by stereomicroscopy before it was cut parallel to the load direction for additional investigation by a Hitachi SU-70 scanning electron microscope (SEM). No samples were etched. Orientation imaging microscopy (OIM) was performed by use of an electron backscatter diffraction (EBSD) system by HKL technology.

\section{Results and Discussion}

LCF Behaviour. Fig. 1 displays results from the LCF tests where the $\Delta \epsilon_{\text {mech }}$ is plotted versus cycles to failure, $N_{f}$, for all tested specimens. It can be seen that the $\langle 001\rangle$ direction shows the highest number of cycles to failure, followed by the $\langle 011\rangle$ and $\langle 111\rangle$ directions, when equivalent strain ranges are compared. This is a direct consequence from the fact that specimens with a low stiffness in the load direction are favoured during strain-controlled fatigue, and that the $\langle 001\rangle$ direction has the lowest stiffness of the three directions.

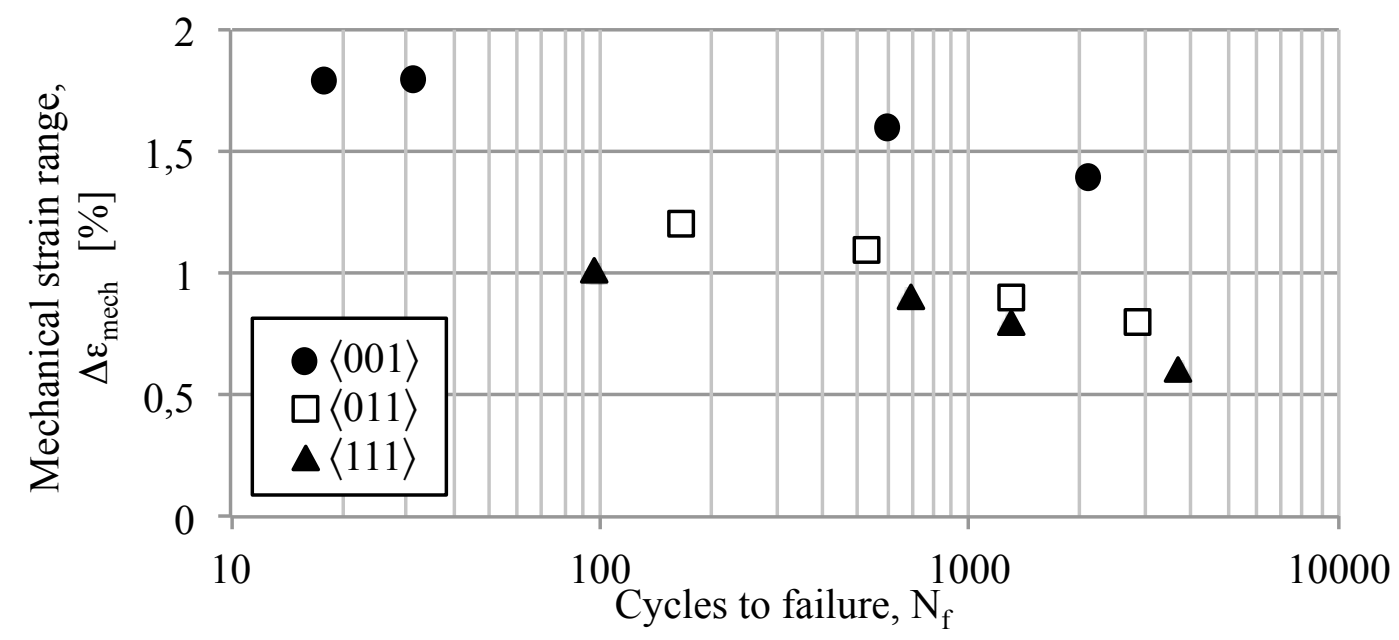

Fig. 1: Results from the LCF tests for all crystal orientations; mechanical strain range, $\Delta \epsilon_{m e c h}$, versus cycles to failure, $N_{f}$. 
During the initial cycles of the LCF tests, a serrated yielding behaviour is observed for the $\langle 011\rangle$ and $\langle 111\rangle$ directions, both in tension and compression, see Fig. 2 (a) for the first cycle for one of the $\langle 011\rangle$ oriented specimens. The serrated yielding continues for a number of cycles for both the $\langle 011\rangle$ and $\langle 111\rangle$ directions. For the $\langle 111\rangle$ direction, a hysteresis loop with a stable yielding is not reached until approximately 15 cycles, while for the $\langle 011\rangle$ direction it takes roughly 20 cycles to reach a hysteresis loop with a stable yielding. However, regarding the $\langle 001\rangle$ direction, no serrations are detected when applying the LCF cycles, instead this direction shows a more stable yielding. A previous study [8] suggests that a serrated yielding behaviour during montonic loading by the $\langle 011\rangle$ direction partly is attributed to dynamic strain ageing (DSA), and it may be assumed that this occurs during LCF loadings as well.

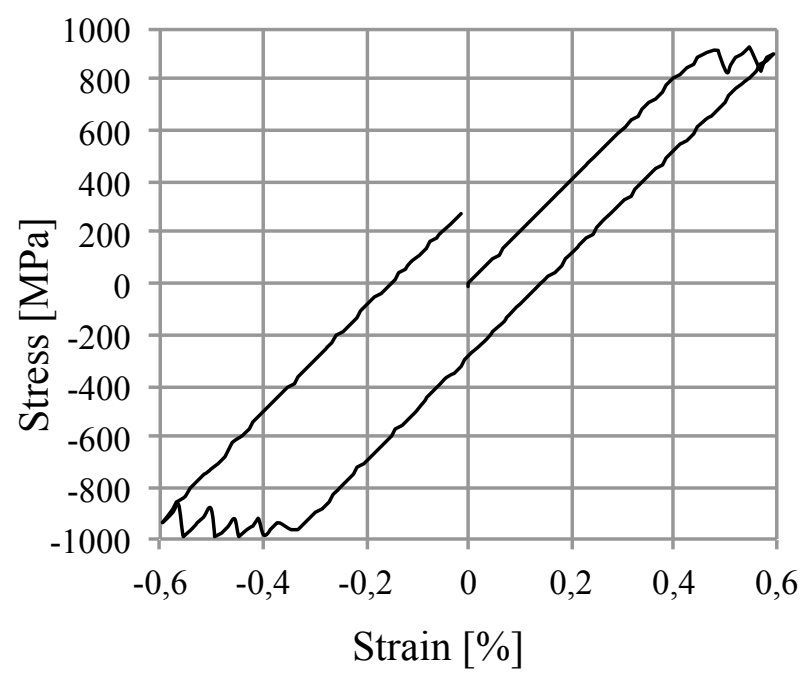

(a)

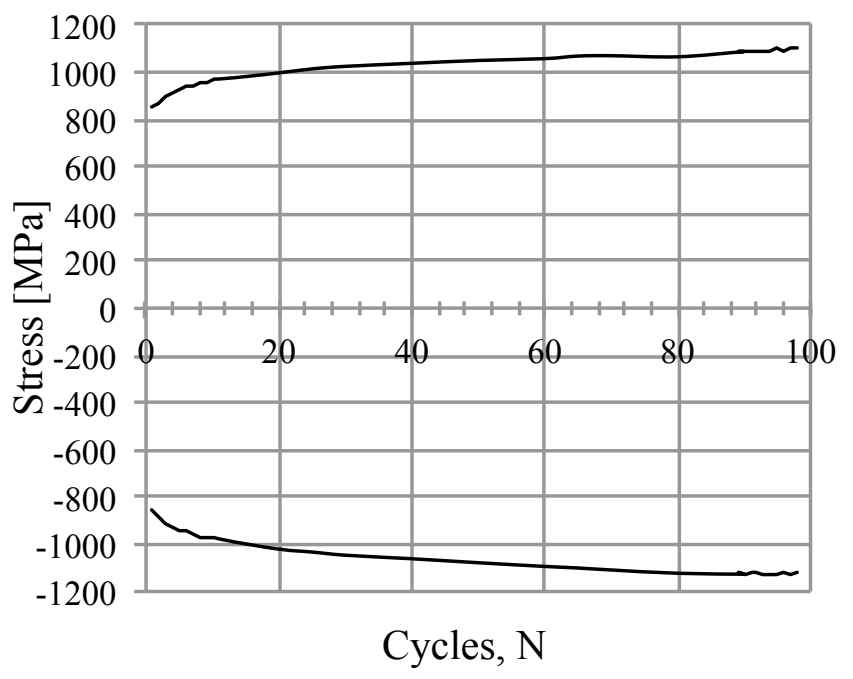

(b)

Fig. 2: (a) Serrated yielding during the first hysteresis loop for the $\langle 011\rangle$ direction subjected to $\Delta \epsilon_{\text {mech }}$ $=1.2 \%$, (b) cyclic hardening of the $\langle 111\rangle$ oriented specimen subjected to $\Delta \epsilon_{\text {mech }}=1 \%$.

Another difference between the three directions is that the $\langle 111\rangle$ direction exhibits a cyclic hardening, see Fig. 2 (b). The $\langle 011\rangle$ direction shows less hardening compared to the $\langle 111\rangle$ direction, while the stress state for the $\langle 001\rangle$ direction is rather constant until crack initiation. A cyclic stress-strain curve, where the stress at mid-life $\left(N_{f} / 2\right)$ is plotted versus strain, is established for each direction, see Fig. 3. In that figure, also monotonic stress-strain curves from a previous study [8] are added, to be able to compare cyclic and montonic stress-strain curves. Generally, the cyclic stress-strain results agree well with the monotonic results for all tested directions. However, it is once again visible that both the $\langle 011\rangle$ and $\langle 111\rangle$ directions seem to harden during cyclic loading, see Fig. 3 (b) and (c), while the tendency for the $\langle 001\rangle$ direction rather is cyclic softening during LCF compared to the monotonic tests, see Fig. 3 (a).

A cyclic tension/compression asymmetry is observed when studying the mid-life tensile $(\mathrm{T})$ and compressive (C) stresses. Fig. 4 displays a summary of the mid-life stresses for all crystal orientations tested in this study. For the $\langle 001\rangle$ direction $\mathrm{T}>\mathrm{C}$ at mid-life, while for the $\langle 011\rangle$ direction an opposite behaviour is observed. Regarding the $\langle 111\rangle$ direction both types of asymmetry are prevalent. For this direction the asymmetry seems to be strain range dependent, where low $\Delta \epsilon_{\text {mech }}(0.6$ and $0.8 \%)$ leads to $\mathrm{T}>\mathrm{C}$, while for higher $\Delta \epsilon_{\text {mech }}(0.9$ and $1.0 \%) ; \mathrm{C}>\mathrm{T}$ at mid-life. Jiao et al. [9] studied the cyclic tension/compression asymmetry for a $\langle 001\rangle$ oriented specimen during LCF and found that the asymmetry was both temperature and strain rate dependent. In that study, for LCF at $650{ }^{\circ} \mathrm{C}$ and strain rates similar as our study; $\mathrm{T}>\mathrm{C}$, while the asymmetry changed to $\mathrm{C}>\mathrm{T}$ when increasing 

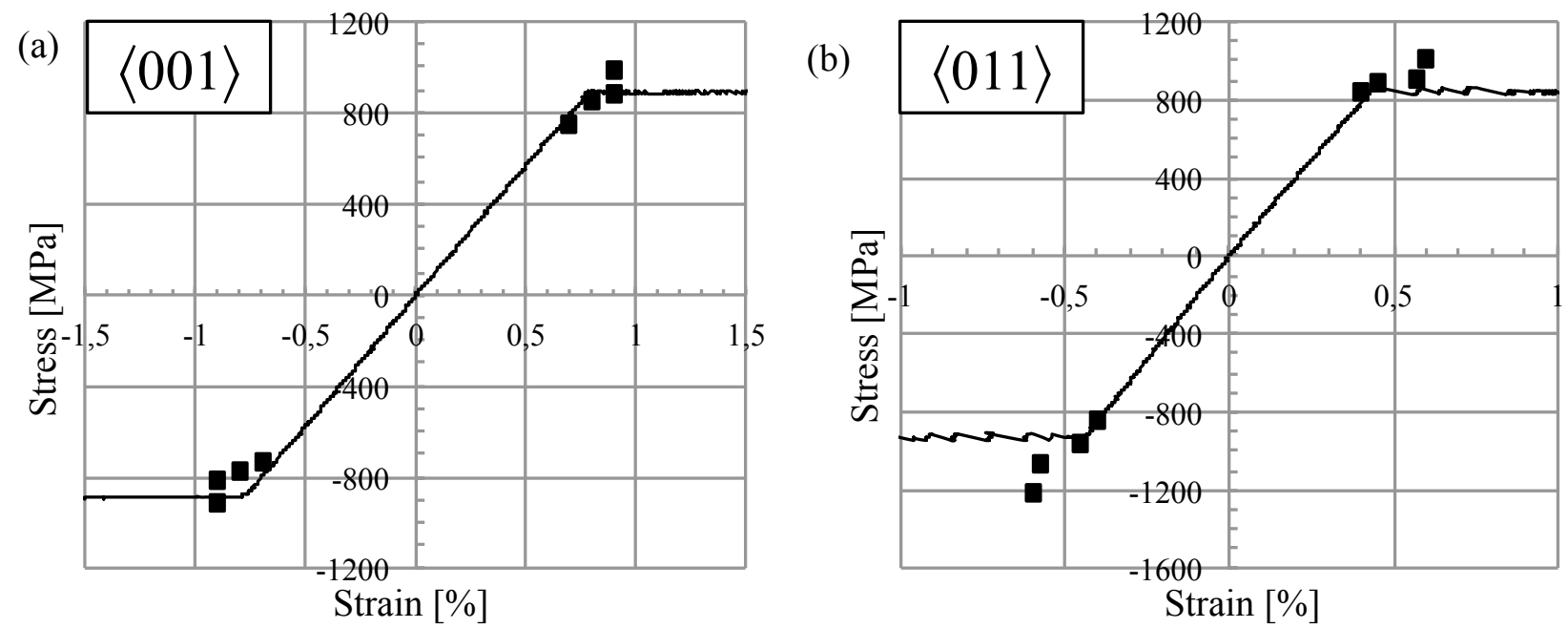

(c)

- Cyclic

— Monotonic

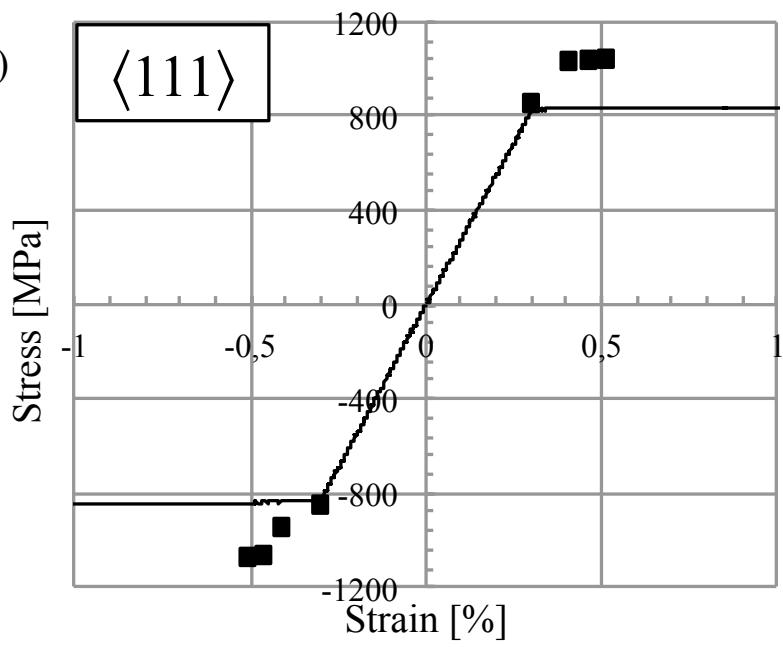

Fig. 3: A comparison between cyclic and monotonic stress-strain curves for the $\langle 001\rangle$ (a), $\langle 011\rangle$ (b) and $\langle 111\rangle$ (c) directions respectivley. The monotonic stress-strain curves are taken from [8].

the temperature and decreasing the strain rate. Hence, the results from our study agrees well with the previous study. In addition, this study shows that the $\langle 011\rangle$ direction show a greater asymmetry compared to the $\langle 001\rangle$ with $\mathrm{C}>\mathrm{T}$ and that the asymmetry for the $\langle 111\rangle$ direction seems to be strain range dependent.

Microscopy. By stereomicroscope investigation, crystallographic deformation bands on the specimen surfaces are found for the $\langle 001\rangle$ and $\langle 011\rangle$ directions only, see Fig. 5. The $\langle 111\rangle$ direction does not show any crystallographic deformation bands on the surfaces. Fractography investigation shows that fractures are partly random and partly crystallographic for all crystal orientations, hence no significant difference between the crystal orientations can be observed in fracture behaviour.

Investigation by SEM shows severe plastic deformation within the $\gamma / \gamma^{\prime}$-microstructure and sometimes this deformation is crystallographic. Fig. 6 displays a backscattered electron image showing an area close to the fracture surface for a $\langle 001\rangle$ oriented specimen. In Fig. 6 (b) a magnification of the crystallographic deformation from (a) is shown. When performing OIM by EBSD on this area, results show very small orientation differences, only up to $5^{\circ}$. Hence, even if the deformation in Fig. 6 (b) very much looks like deformation twinnning this cannot be proven with the equipment available for this study. In addition to the crystallographic deformation, heavy plastic deformation is observed close to the fracture surface and around additional cracks. Fig. 6 (c) shows an additional crack that follows a crystallographic deformation band. In Fig 6 (d) a magnification of the area in front of the crack in (c) is shown. Here it seems that the $\gamma^{\prime}$-precipitates are cut. Further, Fig. 6 (e) displays an EBSD map 


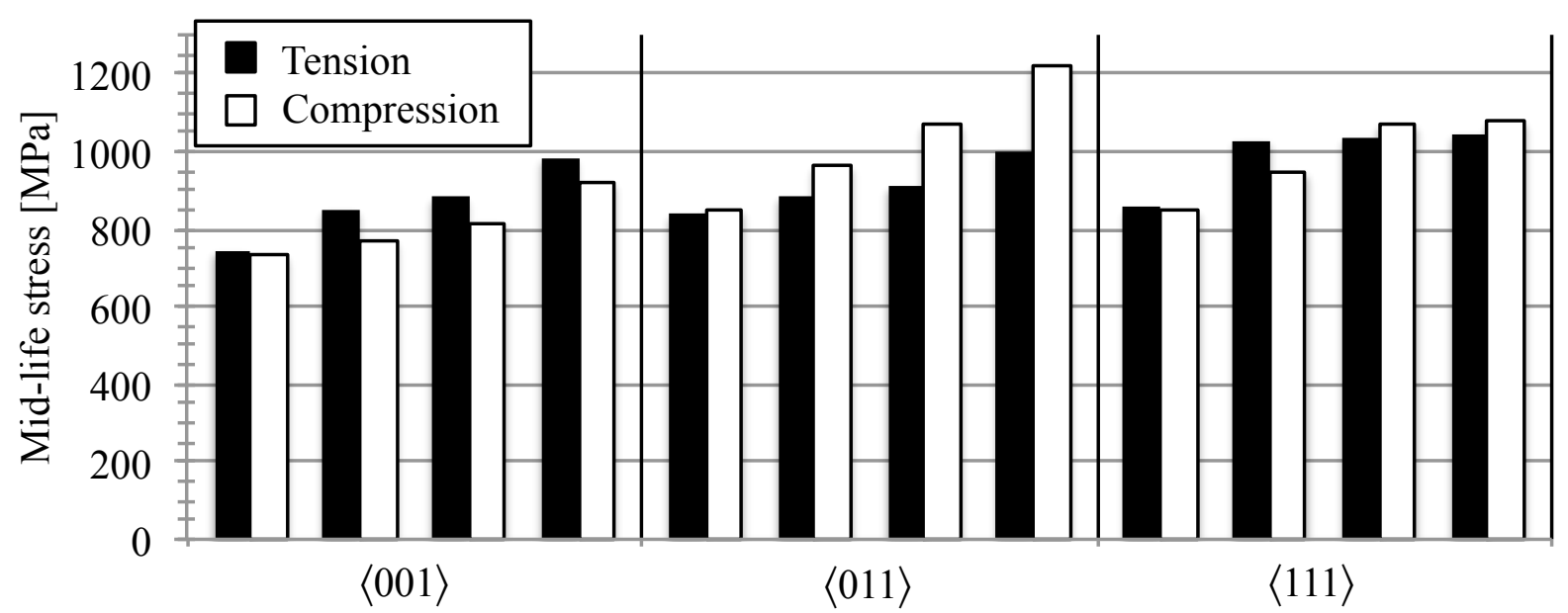

Fig. 4: Mid-life stresses (stresses at $N_{f} / 2$ ) for each specimen for the different crystal orientations. A clear tension/compression asymmetry during LCF can be observed.

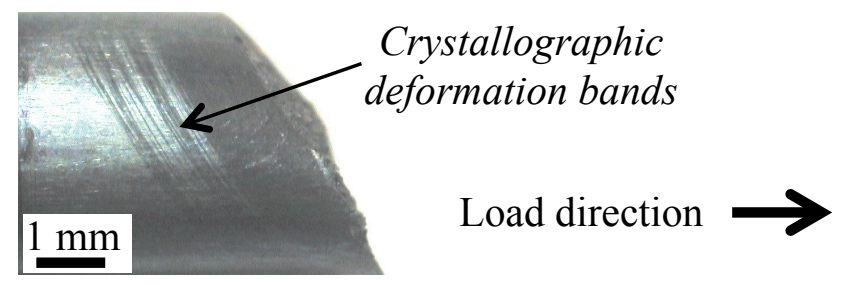

Fig. 5: Crystallographic deformation bands on an $\langle 011\rangle$ oriented specimen $\left(\Delta \epsilon_{\text {mech }}=1.1 \%\right)$.

of the local misorientations of the area around the crack. Here it is visible that heavy plastic deformation surrounds the crack and once again when performing OIM, only small orientation differences are found in front of the crack.

\section{Summary and conclusions}

From LCF tests at $500{ }^{\circ} \mathrm{C}$, the $\langle 001\rangle$ direction shows the highest number of cycles to failure, followed by the $\langle 011\rangle$ and $\langle 111\rangle$ directions, when equivalent strain ranges are compared. Both the $\langle 011\rangle$ and $\langle 111\rangle$ directions show a serrated yielding behaviour in both tension and compression during the first 15-20 cycles during the tests. In addition, a cyclic tension/compression asymmetry in mid-life stress is observed for all tested crystal orientations where the $\langle 011\rangle$ direction shows the highest degree of asymmetry. When comparing cyclic stress-strain curve with monotonic curves from a previous study, it is visible that the $\langle 011\rangle$ and $\langle 111\rangle$ directions exhibit cyclic hardening during LCF. Microstructure investigation shows that cracks sometimes seems to propagate along crystallographic deformation bands and sometimes more randomly. When comparing the three crystal orientations, no significant differences in deformation and damage mechanisms are found.

\section{Acknowledgements}

Siemens Industrial Turbomachinery in Finspång, Sweden and the Swedish Energy Agency have financed this work through the Research Consortium of Materials Technology for Thermal Energy processes (Grant No. KME-502) for which they are greatly acknowledged. Also AFM and Agora Materiae are acknowledged for their support (Faculty grant SFO-MAT-LiU\#2009-00971). Associate professor $\mathrm{Ru}$ Lin Peng is acknowledged for her help regarding the EBSD analysis. 


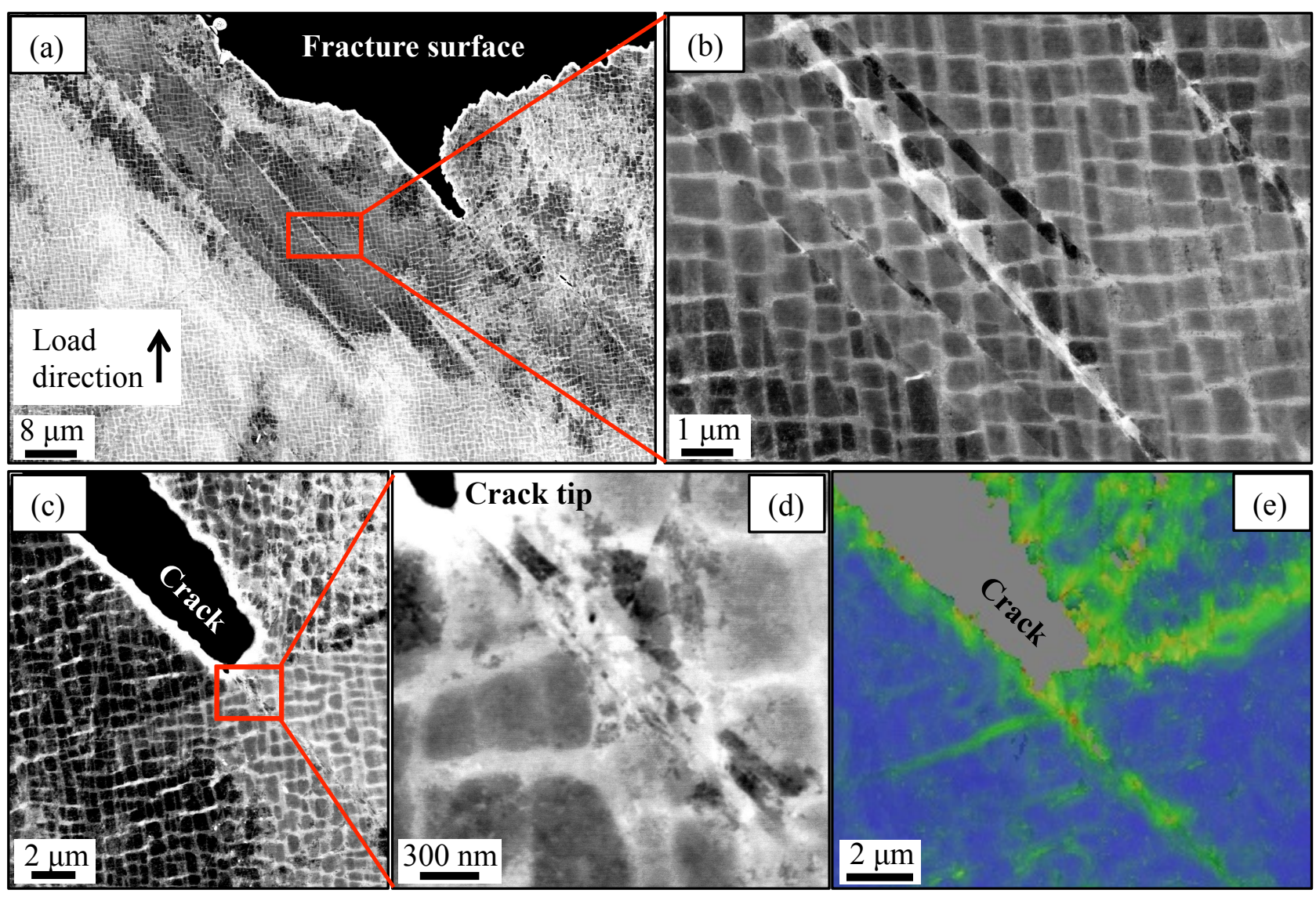

Fig. 6: Backscattered electron images showing the $\langle 001\rangle$ oriented specimen subjected to $\Delta \epsilon_{\text {mech }}=1.4$ $\%$ : (a) area close to the fracture surface, (b) magnification of crystallographic deformation in (a), (c) an additional crack (please note: this is not the crack visible in (a)), (d) magnification of area in front of the crack in (c), (e) an EBSD map showing the local misorientation around the crack in (c).

\section{References}

[1] R. C. Reed: The Superalloys - Fundamentals and Applications (Cambridge University Press, U.K 2006).

[2] D. Shi, J. Huang, X. Yang and H. Yu: Int. J. Fatigue Vol. 49 (2013), p. 31

[3] M. Segersäll, J. J. Moverare, K. Simonsson and S. Johansson, in: Superalloys 2012, edited by E. S. Huron, R. C. Reed, M. Hardy, M. J. Mills, R. E. Montero, P. D. Portella and J. Telesman, The Minerals, Metals and Materials Society (2012), p. 215

[4] J. Moverare, S. Johansson and R. C. Reed: Acta Mater. Vol. 57 (2009), p. 2266

[5] T. P. Gabb, G. Welsch, R. V. Miner and J. Gayda: Mater. Sci. Eng. Vol. 108 (1989), p. 189

[6] T. P. Gabb and G. Welsch: Acta Metall. Vol. 37 (1989), p. 2507

[7] S. S. Ezz, D. P. Pope and V. Paidar: Acta Metall. Vol. 30 (1982), p. 921

[8] M. Segersäll and J. J. Moverare: Materials, Vol. 6 (2013), p. 437

[9] F. Jiao, D. Bettge, W. Österle and J. Ziebs: Acta Mater. Vol 44 (1996), p. 3933 